\title{
Article
}

\section{Efeito das fezes bovinas na estrutura do capim-marandu durante as estações do ano}

\author{
Angélica Nunes de Carvalho ${ }^{*}$, Gabriel de Oliveira Rocha ${ }^{1}$, \\ Manoel Eduardo Rozalino Santos ${ }^{1}$, Bruno Nascimento Segatto ${ }^{1}$, \\ Lucas Henrique Sousa Alves ${ }^{1}$, Kathleen Alves Vasconcelos ${ }^{1}$
}

\begin{abstract}
RESUMO
As fezes depositadas pelos bovinos nas pastagens alteram o desenvolvimento e o consumo da planta forrageira, o que tem efeito sobre a estrutura do pasto. Nesse sentido, objetivou-se caracterizar as mudanças que ocorrem nas propriedades estruturais da Urochloa brizantha cv. Marandu (capim-marandu) sob pastejo rotativo como consequência da deposição natural das fezes pelos bovinos na pastagem. Durante as estações do ano, foram avaliados dois locais no piquete, um próximo e outro distante das fezes depositadas pelos bovinos. O delineamento foi em blocos casualizados com quatro repetições, em esquema de parcelas subdivididas no tempo. As avaliações ocorreram nas quatro estações do ano. Nas estações com clima favorável ao crescimento vegetal, o pasto de capim-marandu próximo das fezes apresentou maior altura, massa de forragem e percentagem de colmo vivo em comparação ao pasto distante das fezes. No inverno, não ocorreram efeitos das fezes sobre a estrutura do pasto, que teve suas características estruturais comprometidas quando comparadas à primavera e ao verão. $\mathrm{O}$ efeito das fezes sobre a estrutura do capim-marandu depende da época do ano.
\end{abstract}

Palavras-chave: altura do pasto; Urochloa brizantha; composição morfológica; índice de área foliar.

\section{Introdução}

A estrutura do pasto consiste no arranjo espacial dos componentes da parte aérea das plantas dentro de uma comunidade (LACA \& LEMAIRE, 2000), dependendo de como o pasto é ofertado para os animais durante o pastejo. Essa estrutura pode ser caracterizada por altura, massa de forragem, composição morfológica, índice de área foliar e número de perfilhos no pasto. Essas variáveis podem sofrer mudanças que alteram o

\footnotetext{
${ }^{1}$ Universidade Federal de Uberlândia, Uberlândia, Minas Gerais, Brasil.

* Corresponding author: angelicanunescoro@hotmail.com. Endereço para correspondência:

Rua Coronel Severiano, 27, Fundinho, Uberlândia - Minas Gerais, Brasil. Cep: 38400-228. Telefone para contato: (34)99780-9182.
} 
microclima no interior do dossel forrageiro e, com efeito, interferem na competição por luz entre as plantas, no crescimento, no florescimento e na senescência do pasto (CARLOTO et al., 2011; NANTES et al., 2013).

No que tange ao animal, a estrutura do pasto modifica o comportamento ingestivo, o consumo diário e, consequentemente, o desempenho dos animais em pastejo (PAULA et al., 2012). Nesse sentido, atualmente, o manejo das pastagens deve ser planejado para produzir um pasto com estruturas que aperfeiçoem o comportamento ingestivo dos animais em pastejo, o que também atende aos princípios de bem-estar na criação animal.

A deposição de fezes e sua posterior mineralização pode aumentar a disponibilidade de nutrientes no solo (BRAZ et al., 2002) com efeitos positivos sobre o desenvolvimento do pasto. Desse modo, as fezes depositadas pelos bovinos representam uma importante forma de ciclagem de nutrientes na pastagem, o que pode contribuir para a sua sustentabilidade ambiental. Ademais, as fezes também resultam em rejeição pelos bovinos das plantas em seu entorno (WILLIANS \& HAYNES, 1995). Essa rejeição ocorre, inicialmente, pelo odor e posteriormente pela estrutura da pastagem, pois o pasto alcança maior altura e fica com uma estrutura/morfologia desfavorável ao pastejo, ou seja, há maior comprimento do colmo (SANTOS et al., 2011).

É possível que os efeitos das fezes sobre a estrutura do pasto sejam diferentes ao longo das estações do ano, haja vista que os fatores abióticos de crescimento, tais como a disponibilidade de água no solo, temperatura, fotoperíodo, dentre outros, são sazonais e modulam o desenvolvimento vegetal (FAGUNDES et al., 2006; LARA \& PEDREIRA, 2011).

Este trabalho foi desenvolvido com o objetivo de caracterizar, durante as estações do ano, as modificações na estrutura do pasto causadas pela deposição de fezes por bovinos na pastagem. 


\section{Material e métodos}

$\mathrm{O}$ experimento foi realizado em um piquete de aproximadamente três hectares com Urochloa brizantha cv. Marandu (capim-marandu), estabelecida em 2000, na Fazenda Capim-branco, da Universidade Federal de Uberlândia, situada em Uberlândia, Minas Gerais (18 $53^{\prime} 19^{\prime \prime}$ S, 48²0'57" W e 863 metros de altitude). O clima da região é tropical de altitude (ALVARES et al., 2013), com estação seca e chuvosa bem definida, sendo a temperatura e a precipitação média anual de $22,3{ }^{\circ} \mathrm{C}$ e $1.584 \mathrm{~mm}$.

O período de realização do experimento foi de outubro de 2011 a setembro de 2012. As informações referentes às condições climáticas, durante o período experimental, foram monitoradas na estação meteorológica localizada aproximadamente a $200 \mathrm{~m}$ da área experimental (Figura 1).

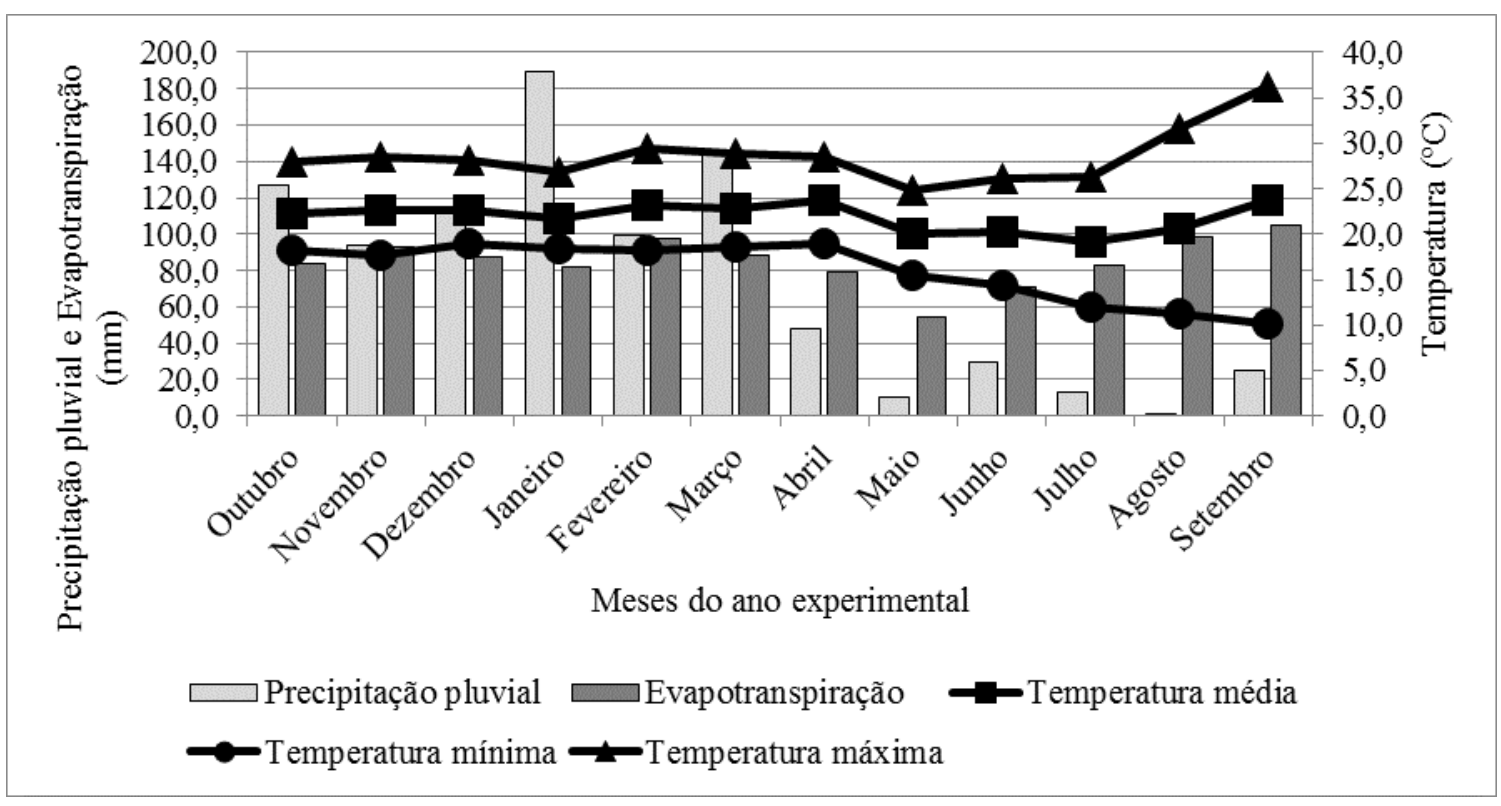

Figura 1. Médias mensais de temperaturas diárias, precipitação pluvial e evapotranspiração durante o período de outubro de 2011 a setembro de 2012. 
Antes da implantação do experimento, foram retiradas amostras de solo para a análise do nível de fertilidade. A análise química do solo, no início do experimento e na camada de 0 a $20 \mathrm{~cm}$, apresentou os seguintes resultados: $\mathrm{pH}$ em $\mathrm{H}_{2} \mathrm{O}: 5,5 ; \mathrm{P}: 1,3$ (Mehlich-1) e $\mathrm{K}: 75$ mg dm³ ${ }^{-3} \mathrm{Ca}^{2+}$ : 1,7; $\mathrm{Mg}^{2+}: 1,1 \mathrm{e} \mathrm{Al}^{3+}:$ 0,0 cmolc.dm-3 $\left(\mathrm{KCl} 1 \mathrm{~mol} \mathrm{~L}^{-1}\right)$.

Com base nos resultados de análise de solo, não foi necessário efetuar a calagem na pastagem. As adubações fosfatada, nitrogenada e potássica foram realizadas em outubro de 2011, com a aplicação de $90 \mathrm{~kg} \mathrm{ha}^{-1}$ de N, 70 $\mathrm{kg} \mathrm{ha}{ }^{-1}$ de $\mathrm{P}_{2} \mathrm{O}_{5}$ e $30 \mathrm{~kg}$ de $\mathrm{K}_{2} \mathrm{O} \mathrm{ha}^{-1}$, utilizando como fonte o formulado NPK 04:30:16 e a ureia. Também foram realizadas mais duas aplicações de adubo nitrogenado na pastagem, cada uma correspondente a $50 \mathrm{~kg}^{\mathrm{h}} \mathrm{a}^{-1}$ de $\mathrm{N}$ nos meses de janeiro e março. As adubações foram realizadas de acordo com as recomendações de Cantarutti et al. (1999) para um sistema de médio nível tecnológico.

O piquete foi manejado em lotação intermitente com taxa de lotação variável, utilizando-se bovinos da raça Nelore. Os períodos de descanso e de ocupação foram variáveis nas distintas estações do ano, e o manejo do pastejo foi caracterizado pela adoção de alturas de pasto de, em média, 27 e $16 \mathrm{~cm}$ em pré e pós-pastejo, respectivamente (Tabela 1).

Tabela 1. Informações sobre o manejo do pastejo nos meses do ano em que as avaliações foram realizadas no pasto de capim-marandu.

\begin{tabular}{|c|c|c|c|c|}
\hline \multirow{2}{*}{ Mês } & \multirow{2}{*}{ Estação } & \multicolumn{2}{|c|}{ Altura média $(\mathrm{cm})$} & \multirow{2}{*}{ - Período de ocupação e caracterização dos animais } \\
\hline & & pré-pastejo & pós-pastejo & \\
\hline \multirow{3}{*}{ Novembro } & \multirow{3}{*}{ Primavera } & \multirow{3}{*}{30} & \multirow{3}{*}{17} & Seis dias \\
\hline & & & & $1^{\circ}$ lote: 52 novilhos $(270 \mathrm{~kg})$ por cinco dias \\
\hline & & & & $2^{\circ}$ lote: 20 vacas $(480 \mathrm{~kg})$ por um dia \\
\hline \multirow{2}{*}{ Janeiro } & \multirow{2}{*}{ Verão } & \multirow{2}{*}{28} & \multirow{2}{*}{16} & Dez dias \\
\hline & & & & Único lote: 51 novilhos (300 kg) \\
\hline \multirow{2}{*}{ Março } & \multirow{2}{*}{ Outono } & \multirow{2}{*}{26} & \multirow{2}{*}{14} & Dez dias \\
\hline & & & & Único lote: 51 novilhos (380 kg) \\
\hline \multirow{2}{*}{ Agosto } & \multirow{2}{*}{ Inverno } & \multirow{2}{*}{25} & \multirow{2}{*}{15} & Três dias \\
\hline & & & & Único lote: 20 vacas (480 kg) \\
\hline
\end{tabular}


Durante todo o período de ocupação do piquete, nas quatro estações do ano, os bovinos tiveram acesso ao concentrado e o consumo estimado variou entre 1,0 e $1,5 \mathrm{~kg}$ animal/dia ${ }^{-1}$. Para a implementação do experimento, foram demarcadas quatro faixas, sem o uso de cercas, utilizando-se como referência as curvas de nível existentes na área do piquete.

Durante as estações do ano, em cada faixa, foram avaliados dois locais no piquete, um próximo e outro distante das fezes depositadas naturalmente pelos bovinos (bolo fecal) durante o período de ocupação do piquete. Considerou-se próximo das fezes o local imediatamente adjacente a elas, enquanto o local distante correspondeu àquele em que, em um raio de cerca de dois metros, não havia presença de fezes. O delineamento experimental foi em blocos ao acaso, com quatro repetições (faixas), e o critério para a definição dos blocos foi a variação de relevo existente na área experimental.

As avaliações foram realizadas ao término do período de descanso e, em cada estação, ocorreram em um único ciclo de pastejo. Dessa forma, para as estações de primavera, verão, outono e inverno, os dias de avaliação foram os de 20/12/2011; 02/03/2012; 19/04/2012; e 28/09/2012, respectivamente.

O número de perfilhos foi determinado pela contagem dos perfilhos vivos contidos no interior de uma moldura de $25 \mathrm{~cm}$ por $50 \mathrm{~cm}$. Para isso, seis contagens foram realizadas por faixa, sendo três em locais próximos e três em locais distantes das fezes depositadas pelos bovinos. A altura do pasto foi medida com régua graduada, considerando-se a distância desde a superfície do solo até as folhas vivas localizadas mais altas no pasto. A medição da altura dos pastos ocorreu em dez locais distantes e em dez locais próximos das fezes em cada faixa.

Em cada faixa, também foram colhidas, ao nível da superfície do solo e com uso de um quadrado com $50 \mathrm{~cm}$ de lado, seis amostras de massa de forragem, sendo três próximas e três distantes das fezes. Essas amostras foram separadas em lâmina foliar viva, colmo vivo e tecido morto. A região 
da lâmina foliar que não apresentava sinais de senescência (órgão de cor verde) foi incorporada à fração lâmina foliar viva. A região da lâmina foliar, bem como os colmos com amarelecimento e/ou necrosamento do órgão, foram incorporados à fração tecido morto. A bainha foliar viva e a inflorescência, quando presentes, foram quantificadas na fração colmo vivo. As subamostras dos componentes morfológicos foram acondicionadas em sacos de papel identificados, colocados na estufa de ventilação forçada a $65^{\circ} \mathrm{C}$, por 72 horas, e, em seguida, pesados. Com esses dados, foram calculadas a massa de forragem total e as percentagens dos componentes morfológicos da forragem.

Em cada faixa no piquete, 50 lâminas foliares vivas foram coletadas aleatoriamente e acondicionadas em sacos plásticos identificados. Uma pequena parte das extremidades dessas lâminas foliares (ápice e base) foi cortada e descartada, de modo que se obteve um segmento de lâmina foliar aproximadamente retangular. A largura e o comprimento de cada segmento foram mensurados e, pelo produto dessas dimensões, obteve-se sua área foliar. Estes foram colocados em uma estufa de ventilação forçada a $65{ }^{\circ} \mathrm{C}$, por 72 horas e, em seguida, pesados. Com esses dados, foi calculada a área foliar específica ( $\mathrm{cm}^{2}$ de lâmina foliar $\mathrm{g}^{-1}$ de lâmina foliar). $\mathrm{O}$ índice de área foliar foi calculado pelo produto da área foliar específica pela massa de lâmina foliar viva do pasto.

Os dados obtidos foram submetidos à análise de variância, em delineamento de blocos casualizados e em esquema de parcelas subdivididas no tempo. Os locais do pasto corresponderam às parcelas e, as estações do ano, às subparcelas. Quando a interação entre os fatores (local do pasto e estação do ano) não foi significativa, realizou-se a comparação entre as médias marginais dos níveis do fator primário (local do pasto) ou secundário (estação do ano). Quando a interação entre os fatores foi significativa, foi realizada a comparação dos níveis de um fator em separado para cada nível do outro fator. As análises foram feitas com o teste de Student Newman 
Keuls ao nível de significância de até 5\% de probabilidade para ocorrência do erro tipo I.

\section{Resultados e discussão}

O número de perfilhos vivos foi maior no verão e no outono quando comparado à primavera e ao inverno. Esse número não é influenciado pela distância do bolo fecal (Tabela 2).

Tabela 2. Número de perfilhos vivos ao término do período de descanso do capim-marandu próximo ou distante das fezes dos bovinos durante as estações do ano

\begin{tabular}{llllll}
\hline \multirow{2}{*}{ Local } & \multicolumn{2}{l}{ Estação do ano } & \multicolumn{2}{l}{ Média } \\
\cline { 2 - 5 } & Primavera & Verão & Outono & Inverno & \\
\hline Próximo das fezes & 697 & 897 & 903 & 678 & $794 \mathrm{~A}$ \\
Distante das fezes & 711 & 910 & 891 & 611 & $781 \mathrm{~A}$ \\
Média & $704 \mathrm{~b}$ & $904 \mathrm{a}$ & $897 \mathrm{a}$ & $645 \mathrm{~b}$ & \\
\hline
\end{tabular}

Médias seguidas de letras distintas, minúscula na linha e maiúscula na coluna, diferem pelo teste de Student Newman Keuls $(\mathrm{P}<0,05)$.

Provavelmente, nessas épocas, com fatores propícios para o crescimento da forragem, houve maior disponibilidade de nutrientes no solo, tal como o nitrogênio, em virtude da mineralização das fezes (BRAZ et al., 2002). Isso poderia estimular o perfilhamento da gramínea nesse local do pasto, haja vista que o aumento do aporte de nutrientes no solo resulta em uma maior densidade populacional de perfilhos em pastos manejados baixos (FAGUNDES et al., 2006). Entretanto, o aumento da disponibilidade de nutrientes no solo também causa incremento na taxa de crescimento do pasto (MOREIRA et al., 2009) que, assim, alcança maior altura, principalmente nas estações com clima favorável ao crescimento da planta, tal como a primavera, o verão e o outono (Tabela 4). Essa maior altura das plantas próximas das fezes gera um microclima mais sombreado no interior do dossel, o que, de acordo com Sbrissia \& Silva (2008), pode inibir o desenvolvimento das gemas basais em novos perfilhos. 
Desse modo, pode ter ocorrido uma compensação no local próximo das fezes, em que, inicialmente, a maior disponibilização de nutrientes estimulou o perfilhamento, mas, posteriormente, com o maior crescimento da planta, houve uma diminuição da incidência de luz na base do dossel, o que pode ter inibido o perfilhamento ou até mesmo ter causado a morte dos perfilhos mais jovens e de menor tamanho (SBRISSIA \& SILVA, 2008). Essa compensação anulou o efeito das fezes sobre o número de perfilhos, de modo que seu valor foi similar ao observado no local distante das fezes (Tabela 2).

$\mathrm{O}$ índice de área foliar (IAF) do capim-marandu foi influenciado de forma isolada pela estação do ano, de maneira que não houve efeito $(\mathrm{P}>0,05)$ do local do pasto sobre essa variável-resposta. Por outro lado, maior IAF ocorreu na primavera, com valores intermediários no verão e no outono e inferiores no inverno (Tabela 3).

Tabela 3. Índice de área foliar ao término do período de descanso do capim-marandu próximo ou distante das fezes dos bovinos durante as estações do ano

\begin{tabular}{llllll}
\hline \multirow{2}{*}{ Local } & \multicolumn{2}{l}{ Estação do ano } & & \multirow{2}{*}{ Média } \\
\cline { 2 - 5 } & Primavera & Verão & Outono & Inverno & \\
\hline Próximo das fezes & 4,8 & 4,5 & 3,9 & 1,2 & $3,6 \mathrm{~A}$ \\
Distante das fezes & 5,3 & 3,7 & 3,7 & 1,2 & $3,5 \mathrm{~A}$ \\
Média & $5,1 \mathrm{a}$ & $4,1 \mathrm{~b}$ & $3,8 \mathrm{~b}$ & $1,2 \mathrm{c}$ & \\
\hline
\end{tabular}

Médias seguidas de letras distintas, minúscula na linha e maiúscula na coluna, diferem pelo teste de Student Newman Keuls $(\mathrm{P}<0,05)$.

O índice de área foliar (IAF) do pasto é formado por três características: densidade populacional de perfilho, número de folha viva por perfilho e área da lâmina foliar. Dentre estes, o número de perfilhos é o principal componente do IAF (SBRISSIA \& SILVA, 2008). Como as fezes não influenciaram a densidade populacional de perfilho (Tabela 2), esse mesmo padrão de resposta também foi observado para o IAF (Tabela 3).

Quanto à altura do capim-marandu, houve um efeito $(\mathrm{P}<0,05)$ de interação entre os fatores estudados. Na primavera, no verão e no outono, o capim foi $(\mathrm{P}<0,05)$ mais alto próximo do que distante das fezes. Contudo, no 
inverno, os valores de altura do pasto foram semelhantes $(\mathrm{P}>0,05)$ nos locais avaliados. Próximo das fezes, a altura do pasto foi $(\mathrm{P}<0,05)$ maior no verão e menor no inverno, com valores intermediários na primavera e no outono. No local distante das fezes, o capim-marandu apresentou $(\mathrm{P}<0,05)$ maior altura no verão em comparação às demais estações do ano (Tabela 4).

Tabela 4. Altura do capim-marandu $(\mathrm{cm})$ ao término do período de descanso próximo ou distante das fezes dos bovinos durante as estações do ano

\begin{tabular}{llllll}
\hline \multirow{2}{*}{ Local } & \multicolumn{2}{l}{ Estação do ano } & & \multirow{2}{*}{ Média } \\
\cline { 2 - 5 } & Primavera & Verão & Outono & Inverno & \\
\hline Próximo das fezes & $30 \mathrm{bA}$ & $35 \mathrm{aA}$ & $32 \mathrm{bA}$ & $23 \mathrm{cA}$ & 30 \\
Distante das fezes & $25 \mathrm{bB}$ & $29 \mathrm{aB}$ & $25 \mathrm{bB}$ & $24 \mathrm{bA}$ & 26 \\
Média & 28 & 32 & 29 & 24 & \\
\hline
\end{tabular}

Médias seguidas de letras distintas, minúscula na linha e maiúscula na coluna, diferem pelo teste de Student Newman Keuls $(\mathrm{P}<0,05)$.

Da mesma forma que a altura do pasto (Tabela 4), também houve interação dos fatores estudados sobre a massa de forragem. No outono e no inverno a massa de forragem foi similar $(\mathrm{P}>0,05)$ entre os locais próximos e distantes das fezes. Nas demais estações, o local próximo das fezes possuiu $(\mathrm{P}<0,05)$ superior massa de forragem em relação ao local distante. No local próximo das fezes, a maior massa de forragem foi observada $(\mathrm{P}<0,05)$ no outono e no verão, enquanto no local distante, a superior massa de forragem ocorreu apenas no verão. $\mathrm{O}$ inverno foi a estação com inferior $(\mathrm{P}<0,05)$ massa de forragem independentemente do local avaliado (Tabela 5).

Tabela 5. Massa de forragem ( $\mathrm{kg} / \mathrm{ha}$ de MS) ao término do período de descanso do pasto de capim-marandu próximo ou distante das fezes dos bovinos durante as estações do ano

\begin{tabular}{llllll}
\hline \multirow{2}{*}{ Local } & \multicolumn{2}{l}{ Estação do ano } & & \multirow{2}{*}{ Média } \\
\cline { 2 - 5 } & Primavera & Verão & Outono & Inverno & \\
\hline Próximo das fezes & $7060 \mathrm{abA}$ & $7570 \mathrm{aA}$ & $7360 \mathrm{aA}$ & $6659 \mathrm{bA}$ & 7162 \\
Distante das fezes & $5487 \mathrm{cB}$ & $5514 \mathrm{cB}$ & $7549 \mathrm{aA}$ & $7061 \mathrm{bA}$ & 6403 \\
Média & 6274 & 6542 & 7455 & 6860 & \\
\hline
\end{tabular}

Médias seguidas de letras distintas, minúscula na linha e maiúscula na coluna, diferem pelo teste de Student Newman Keuls $(\mathrm{P}<0,05)$. 
Em relação à composição morfológica do capim-marandu, não houve $(\mathrm{P}>0,05)$ interação entre o local do pasto e a estação do ano para as percentagens de lâmina foliar viva e de tecido morto. Para essas duas variáveis, as respostas não foram $(\mathrm{P}>0,05)$ modificadas pelas fezes dos bovinos. Os valores de percentagem de lâmina foliar viva foram $(\mathrm{P}<0,05)$ decrescentes da primavera até o inverno. De outro modo, a percentagem de tecido morto foi $(\mathrm{P}<0,05)$ superior no inverno, intermediário no outono e inferior na primavera e no verão (Tabela 6).

Tabela 6. Composição morfológica ao término do período de descanso do capim-marandu próximo ou distante das fezes dos bovinos durante as estações do ano

\begin{tabular}{|c|c|c|c|c|c|}
\hline \multirow{2}{*}{ Local } & \multicolumn{4}{|c|}{ Estação do ano } & \multirow{2}{*}{ Média } \\
\hline & Primavera & Verão & Outono & Inverno & \\
\hline & \multicolumn{4}{|c|}{ Lâmina foliar viva (\%) } & \\
\hline Próximo das fezes & 39,9 & 29,2 & 25,6 & 9,0 & $25,9 \mathrm{~A}$ \\
\hline Distante das fezes & 37,9 & 33,1 & 21,0 & 8,4 & $25,1 \mathrm{~A}$ \\
\hline \multirow[t]{2}{*}{ Média } & $38,9 \mathrm{a}$ & $31,2 \mathrm{~b}$ & $23,3 \mathrm{c}$ & $8,7 \mathrm{~d}$ & \\
\hline & \multicolumn{4}{|c|}{ Colmo vivo (\%) } & \\
\hline Próximo das fezes & $30,8 \mathrm{bA}$ & $39,0 \mathrm{aA}$ & 36,9 aA & $13,7 \mathrm{cA}$ & 30,1 \\
\hline Distante das fezes & 33,7 aA & $31,7 \mathrm{aB}$ & $28,0 \mathrm{aB}$ & $14,4 \mathrm{bA}$ & 27,0 \\
\hline \multirow[t]{2}{*}{ Média } & 32,3 & 35,4 & 32,5 & 14,1 & \\
\hline & \multicolumn{4}{|c|}{ Tecido morto (\%) } & \\
\hline Próximo das fezes & 29,3 & 31,8 & 37,5 & 77,3 & $44,0 \mathrm{~A}$ \\
\hline Distante das fezes & 28,4 & 35,2 & 51,0 & 77,2 & $48,0 \mathrm{~A}$ \\
\hline Média & $28,9 \mathrm{c}$ & $33,5 \mathrm{c}$ & $44,3 \mathrm{~b}$ & $77,3 \mathrm{a}$ & \\
\hline
\end{tabular}

Para cada característica, médias seguidas de letras distintas, minúscula na linha e maiúscula na coluna, diferem pelo teste de Student Newman Keuls $(\mathrm{P}<0,05)$.

Para a percentagem de colmo vivo, os efeitos do local do pasto dependeram da estação do ano. Na primavera e no inverno, não ocorreu diferença $(\mathrm{P}>0,05)$ nessa característica entre os locais avaliados. Porém, no verão e no outono foi observado um maior percentual de colmo vivo no local próximo quando comparado ao distante das fezes. Tanto no local próximo quanto no distante das fezes, o menor percentual de colmo vivo foi observado no inverno em comparação às demais estações (Tabela 6).

É possível que o manejo do pastejo adotado, caracterizado pelo término do período de descanso quando o pasto estava com cerca de $25 \mathrm{~cm}$ 
(Tabela 1), tenha diminuído a diferenciação morfológica da planta. De acordo com Giacomini et al. (2009), para o capim-marandu, $25 \mathrm{~cm}$ corresponde à altura em que o pasto intercepta 95\% de luz, uma condição em que a competição por luz no interior do dossel ainda não é acentuada, o que proporciona maior formação de lâminas foliares acima do resíduo póspastejo, em detrimento de colmo e tecidos senescentes. Com isso, as percentagens de lâmina foliar viva e de tecidos mortos não foram influenciadas pela deposição de fezes na pastagem (Tabela 6).

Em condições de cerrado com baixa disponibilidade de água no solo durante o inverno, desencadeia-se a senescência foliar, assim como a morte de perfilhos no pasto. A senescência reduz a superfície de folha susceptível à perda de água via transpiração (PAIVA \& OLIVEIRA, 2006), contribuindo para minimizar a perda de água do vegetal em épocas de escassez desse recurso. Por isso, no inverno foram observados inferiores percentuais de lâmina foliar e de colmo vivos no pasto, contrariamente ao observado para a percentagem de tecido morto (Tabela 6).

Dentre todas as variáveis-respostas avaliadas, aproximadamente $43 \%$ foram influenciadas pela interação entre o pasto e a estação do ano (Tabelas 5 a 7). Isso indica que grande parte dos efeitos das fezes sobre as características estruturais do pasto dependem da época do ano. Nesse sentido, a altura do capim-marandu (Tabela 4), bem como o seu percentual de colmo (Tabela 6), não foram influenciados pelas fezes durante o inverno, possivelmente em razão do clima restritivo ao desenvolvimento da planta forrageira nessa estação (Figura 1). Por outro lado, da primavera até o outono, as condições climáticas mais predisponentes ao crescimento vegetal (Figura 1) permitiram que o capim expressasse os efeitos das fezes depositadas pelos bovinos na pastagem, quais sejam: maior altura e percentuais de colmo vivo. Da mesma forma, a massa de forragem (Tabela 5) também foi maior no local próximo e, em relação ao distante das fezes, 
somente nas estações com clima mais favorável ao desenvolvimento vegetal (primavera e verão).

As fezes sobre o pasto podem estimular o crescimento da planta (SANTOS et al., 2011). Esse estímulo ocorre em estações com clima favorável ao desenvolvimento do pasto. Com maiores temperatura e umidade do solo, o desenvolvimento microbiano é mais intenso, o que contribui para o aumento da taxa de mineralização da matéria orgânica fecal e, com efeito, para a maior disponibilização de nutrientes no solo (BRAZ et al., 2002), o que estimula o crescimento do pasto (SANTOS et al., 2011). Além disso, em condições de maior crescimento do pasto, em geral a oferta de forragem na pastagem é maior para os animais, o que torna esses últimos mais seletivos (NANTES et al., 2013).

De forma contrária, as baixas temperaturas e a ausência de precipitação pluvial, típicas do inverno (Figura 1), diminuem a mineralização da matéria orgânica fecal, o que inibe a disponibilização de nutrientes para o crescimento vegetal. Ademais, o clima desfavorável ao crescimento do pasto geralmente resulta em uma menor oferta de forragem na pastagem, minimizando o grau de rejeição do pasto pelo animal. Por isso, no inverno as fezes geram modificações na estrutura do pasto de forma menos intensa (Tabelas 5 a 7 ).

Dentre os fatores estudados, a estação do ano exerceu efeito sobre todas as variáveis-resposta, ao passo que o local do pasto (fezes) modificou cerca de $43 \%$ das características estruturais avaliadas (Tabelas 3 a 7). Isso demonstra que o clima típico de cada estação do ano tem efeito preponderante sobre a estrutura dos pastos tropicais, conforme observado em outros trabalhos de pesquisa (NANTES et al., 2013; FAGUNDES et al., 2006).

No inverno, devido à escassez de água no solo, bem como às menores temperaturas e o reduzido fotoperíodo (Figura 1), ocorre um menor crescimento do pasto (LARA \& PEDREIRA, 2011). Com isso, o 
perfilhamento é prejudicado (FAGUNDES et al., 2006), o que tem efeito negativo sobre o número de perfilhos no pasto (Tabela 2). Além disso, o crescimento dos perfilhos individuais também é baixo no inverno (FAGUNDES et al., 2006), o que ocasiona a redução no IAF (Tabela 3) e a altura do pasto (Tabela 4) nessa estação do ano.

Segundo McWilliam (1978), as gramíneas tropicais têm crescimento ideal em temperaturas de $30^{\circ} \mathrm{C}$ a $35^{\circ} \mathrm{C}$, e seu crescimento é praticamente nulo quando a temperatura mínima atinge de $10^{\circ} \mathrm{C}$ a $15^{\circ} \mathrm{C}$. $\mathrm{O}$ crescimento da planta também ocorre pelo aumento do volume das células, provocado por fatores bioquímicos, como o afrouxamento da estrutura da parede celular, o aumento da síntese proteica, a respiração e, principalmente, pela ação física da entrada de água nas células, causando grande expansão (turgescência) das estruturas do vegetal (PAIVA \& OLIVEIRA, 2006). Nesse sentido, as baixas temperaturas e a umidade no solo podem explicar os menores números de perfilhos, IAF e altura de plantas no inverno (Tabelas 3 a 5).

Nas estações de primavera e de verão, épocas com alta precipitação e alta disponibilidade de radiação solar, a planta forrageira desenvolve-se em altas taxas (MOREIRA et al., 2009). As chuvas contribuem para a solubilização e, consequentemente, para a disponibilização dos nutrientes do solo para a planta, o que tem efeitos positivos sobre crescimento de vegetal. De fato, neste trabalho, o número de perfilhos vivos (Tabela 2), o índice de área foliar (Tabela 3) e o percentual de lâmina foliar viva (Tabela 6) apresentaram maiores valores nas estações chuvosas (primavera e verão).

Os maiores valores de altura da planta (Tabela 4) no verão, bem como de massa de forragem no verão e no outono (Tabela 5), podem ser atribuídos também ao florescimento do capim-marandu. Nesse estágio de desenvolvimento, o alongamento do colmo é mais expressivo a fim de propiciar maior área de dispersão das sementes. Para o alongamento do colmo e a produção de sementes, os nutrientes da planta são alocados para a sua parte aérea, o que contribui para os maiores valores de altura e massa 
de forragem (Tabelas 5 e 6). Segundo Lara e Pedreira (2011), que avaliaram a taxa de alongamento de colmo durante as estações do ano para as cultivares de Urochloa brizantha Arapoty, Basilisk, Capiporã, Marandu e Xaraés, houve maior alongamento de colmo no capim-marandu no verão devido ao florescimento dessa cultivar nessa época.

Os resultados deste trabalho demonstram que as características estruturais do pasto de capim-marandu são modificadas pela deposição de fezes dos bovinos na pastagem. Como a distribuição dessas fezes é desuniforme na pastagem (BRAZ et al., 2003), a modificação da estrutura do pasto também ocorre de forma heterogênea, o que contribui para a variação da estrutura horizontal do pasto. Adicionalmente, os resultados deste trabalho demonstram que a estação do ano tem efeito pronunciado na estrutura do pasto, caracterizando a variação temporal das características estruturais deste.

\title{
CONCLUSÃO
}

Nas estações com clima favorável ao crescimento vegetal, o pasto de Urochloa brizantha cv. Marandu próximo das fezes apresenta maior altura, massa de forragem e percentagem de colmo vivo, em comparação ao pasto distante das fezes. No inverno não ocorrem efeitos das fezes sobre a estrutura do pasto, que tem suas características estruturais comprometidas quando comparadas à primavera e ao verão.

\section{Structure of marandu palisadegrass near or faraway cattle feces of during seasons}

\begin{abstract}
The feces deposited on pasture by cattle alter the development and consumption of forage plant which has effect on the structure of the pasture. In this sense, the objective was to characterize the changes that occur in the structural characteristics of Urochloa brizantha cv. Marandu under rotational grazing as a result of natural deposition of feces by cattle in the pasture. During the seasons, were evaluated in two locations picket
\end{abstract}


the near and distant other deposited by feces of cattle. The design was a randomized block with four replications. Evaluations occurred in four seasons. At stations with a favorable climate for plant growth, the pasture near the stools had higher height, herbage mass and percentage of live stem, compared to the far pasture from feces. In winter, there was no effect of feces on pasture structure, which had compromised their structural characteristics when compared to spring and summer. The effect of feces on the structure of marandu palisadegrass depends on the time of year.

Keywords: sward height; Urochloa brizantha; morphological composition; leaf area index.

\section{REFERÊNCIAS}

ALVARES, C. A.; STAPE, J. L., SENTElHAS, P. C., GONÇALVES, J. L. M., SPAROVEK, G. Köppen's climate classification map for Brazil. Meteorologische Zeitschrift, v.22, p. 711-728, 2013.

BRAZ, S. P.; NASCIMENTO JÚNIOR, D.; CANTARUTT, R. B.; REGAZZI, A. J.; MARTINS, C. E.; FONSECA, D. M.; BARBOSA, R. A. Aspectos quantitativos do processo de reciclagem de nutrientes pelas fezes de bovinos sob pastejo em pastagem de Brachiaria decumbens na Zona da Mata de Minas Gerais. Revista Brasileira de Zootecnia, v.31, p. 858-865, 2002.

BRAZ, S. P.; NASCIMENTO JÚNIOR, D.; CANTARUTTI, R. B.; MARTINS, C. E.; FONSECA, D. M.; BARBOSA, R. A. Caracterização da distribuição espacial das fezes por bovinos em uma pastagem de Brachiaria decumbens. Revista Brasileira de Zootecnia, v.32, p.787-794, 2003.

CANTARUTTI, R. B.; ALVAREZ V, V. H.; RIBEIRO, A. C. Pastagens. In: RIBEIRO, A. C.; GUIMÃes, P. T. G.; AlvareZ, V. V. H. Comissão de Fertilidade do Solo do Estado de Minas Gerais. Recomendação para o uso de corretivos e fertilizantes em Minas Gerais. Viçosa - 5ª Aproximação. 1999. p.332-341. 
CARLOTO, M. N.; EUClIDES, V. P. B.; MONTAGNER, D. B.; LEMPP, B.; DIFANTE, G. S.; PAULA, C. C. L. Desempenho animal e características de pasto de capim-xaraés sob diferentes intensidades de pastejo, durante o período das águas. Pesquisa agropecuária brasileira, v.46, p.97-104, 2011.

FAGUNDES, J. L.; FONSECA, D. M.; MISTURA, C.; MORAIS, R. V.; VITOR, C. M. T.; GOMIDE, J. A.; NASCIMENTO JÚNIOR, D.; CASAGRANDE, D. R.; COSTA, L. T. Características morfogênicas e estruturais do capim-braquiária em pastagem adubada com nitrogênio avaliadas nas quatro estações do ano. Revista Brasileira de Zootecnia, v.35, p. 21-29, 2006.

GIACOMINI, A. A.; SILVA, S. C.; SARMENTO, D. O. L. ZEFERINO, C. V.; SOUZA JÚNIOR, S. J.; TRINDADE, J. K.; GUARDA, V. A.; NASCIMENTO JÚNIOR, D. Growth of marandu palisadegrass subjected to strategies of intermittent stocking. Scientia Agricola, v.66, p. 733-741, 2009.

LACA, E. A.; LEMAIRE, G. Measuring sward structure. In: T'MANNETJE, L., JONES, R. M. Field and laboratory methods for grassland and animal production research. Wallingford: CABI Publishing, p.103-121, 2000.

LARA, M. A. S.; PEDREIRA, C. G. S. Respostas morfogênicas e estruturais de dosséis de espécies de Braquiária à intensidade de desfolhação. Pesquisa agropecuária brasileira, v.46, p. 760-767, 2011.

MCWILLIAM, J. R. Response of pastures plants to temperature. In: Plant Relation in Pastures. WILSON, J. R. Common wealth Scientific and Industrial Research Organisation (CSIRO), East Melbourne, Australia, p.17-34, 1978.

MOREIRA, L. M.; MARTUSCELLO, J. A.; FONSECA, D. M.; MISTURA, C.; MORAIS, R. V.; RIBEIRO JÚNIOR, J. I. Perfilhamento, acúmulo de forragem e composição bromatológica do capim-braquiária adubado com nitrogênio. Revista Brasileira de Zootecnia, v.38, p.1675-1684, 2009. 
NANTES, N. N.; EUCLIDES, V. P. B.; MONTAGNER, D. B.; LEMPP, B.; BARBOSA, R. A.; GOIS, P. O. Desempenho animal e características de pastos de capim-piatã submetidos a diferentes intensidades de pastejo. Pesquisa agropecuária brasileira, v.48, p.114-121, 2013.

PAIVA, R.; OLIVEIRA, L. M. Fisiologia e produção vegetal. Lavras: UFLA, 2006. 104p.

PAUlA, C. C. L.; EUClides, V. P. B.; MONTAGNER, D. B.; LEMPP, B.; DIFANTE, G. S.; CARLOTO, M. N. Estrutura do dossel, consumo e desempenho animal em pastos de capim-marandu sob lotação contínua. Arquivo Brasileiro de Medicina Veterinária e Zootecnia, v.64, p.169-176, 2012.

SANTOS, M. E. R., FOnsECA, D. M., BRAZ, T. G. S., SILVA, G. P., GOMES, V. M., SILVA, S. P. Influência da localização das fezes nas características morfogênicas e estruturais e no acúmulo de forragem em pastos de capimbraquiária. Revista Brasileira de Zootecnia, v.40, n.1, p.31-38, 2011.

SBRISSIA, A. F.; SILVA, S. C. Compensação tamanho: densidade populacional de perfilhos em pastos de capim-marandu. Revista Brasileira de Zootecnia, v.37, p.35-47, 2008.

WILLIANS, P. H.; HAYNES, R. J. Effect of sheep, deer and cattle dung on herbage production and soil nutrient content. Grass and Forage Science, v.50, p.263-271, 1995. 